\title{
The Demand for Health Care Services in Rural Tanzania
}

\author{
David E. Sahn \\ Cornell University \\ Stephen D. Younger \\ Cornell University \\ Garance Genicot \\ University of California, Irvine
}

February, 2002 


\section{INTRODUCTION}

Public spending on health care remains one of the few uncontroversial roles of government. Even when the state is under internal and external pressure to reduce spending and address account imbalances, expenditures on health services, particularly non-hospital based care, generally find wide-ranging support. What is less clear is whether governments expend money in an appropriate fashion to raise access to, and the use of, health care services. In poor countries, there is an obvious imperative to allocate scarce fiscal resources based on a clear understanding of how investments in the heath sector are going to affect demand; and likewise, to understand how changes in the pricing of public services, and investments in quality improvements, are going to affect consumer decisions about whether and where to seek health care. Likewise, differentiating how poor versus non-poor consumers make decisions about treatment, relative to both pricing and quality, is critical to assessing the equity implications of alternative policies.

This paper examines the pattern of health care demand in rural Tanzania. We use data from the 1993 Human Resources Development Survey (HRDS) to model the health care choices that individuals in Tanzania make when sick or injured. We then consider what these behavioral characteristics imply for public policy. First, we are interested in how changes in the pricing of services will affect their use. ${ }^{1}$ A number of papers examine the determinants of medical care choices in Africa. However, the range of provider choices modeled in these papers is generally more limited ${ }^{2}$ than our study, where we include a broader range of choices than the previous literature: we distinguish between hospital and clinic based care, in both the public and private sector.

Second, in keeping with most recent papers on health care demand, we employ a nested multinominal logit model. However, unlike prior research that uses only a single level nest, we use a two-level nest in our estimates. This innovation permits us to estimate cross-price elasticities that vary for treatment options and the choice of selftreatment. Thus, we get a more accurate picture of the extent to which increased user fees for public health services, for example, increases demand for the no care option (which is presumably a undesirable outcome, on public goods grounds) versus encouraging people to seek care from private providers.

\footnotetext{
${ }^{1}$ One interesting study on the response of consumers to price and quality changes, Litvack and Bodart (1993), finds that consumers would be willing to pay significant amounts for improved quality, sufficiently so that the funds raised would be adequate to finance the improvements demanded. Similarly, Gertler and van der Gaag (1990) find that rural residents in Peru and Côte d'Ivoire are willing to pay for greater proximity to health facilities.

${ }^{2}$ For example, Dor, Gertler and Van Der Gaag's (1987) study on Côte d'Ivoire only identify two provider options, public hospitals and clinics, arguing that there is no private health care in rural Côte d'Ivoire; Mwabu, Ainsworth and Nyamete (1993) distinguish between government, mission and private providers; Dow (1995) between clinics and hospitals in Côte d'Ivoire; and Glick, Razafindravonona and Randretsa (2000) between private, public hospitals and public basic care. Lavy and Quigley (1993) is the one exception, since their model incorporates the choices of hospital inpatient and outpatient, dispensary, pharmacy and clinic.
} 
A third important contribution of this paper is that it examines the impact of the quality of medical care on health demand. The call for improving quality is a favorite of advocates and policy makers, and pervades much of the thinking and actions of international organizations. While the effect of quality on health care outcomes is documented, ${ }^{3}$ the difficulty of examining the impact of quality on the choice of provider has limited research in this area, despite its importance. ${ }^{4}$ Thus, the exploration of quality effects on demand is a particularly important empirical question.

Beyond price and quality effects, we also examine how a series of other characteristics of the household, and individuals, affect their health care choices. The role of education, age, duration of illness, and so forth, provide important insights into the potential opportunities and limitations of public policy to affect patterns of demand.

Even though the HRDS is a national survey, we limit our analysis to rural areas of Tanzania. The discrete choice model assumes that people have a limited number of health care options available to them. This is entirely plausible for rural areas, where distance between facilities is great, so that one is likely to choose the nearest one, and it is also possible to compute a time price for travel. For urban areas, however, it is both difficult to derive a time price, and difficult to define the feasible options among the large number of public and private health care facilities that may well be within a short distance of an individual's home.

The remainder of the paper is organized as follows. In the next section we discuss the methods used and the empirical strategy employed. This is followed by a brief discussion of the data, before presenting the empirical results. We conclude with a summary of the findings, and their implications for policy.

\section{ECONOMETRIC MODEL}

The demand that we model is the selection of a health care provider, given that a person is sick. This is a discrete choice, so our estimates are actually for the probability that one elects a given option. The specification that we use in this paper is a nested multinomial logit model with five options: no care (or self-care), care at a public hospital, care at a private hospital, care at a public clinic, and care at a private clinic.

Our model follows Gertler, Locay, and Sanderson (1987). ${ }^{5}$ For each option there is a function that describes the utility that a person derives from choosing it:

$$
V_{j}=f\left(y-p_{j}\right)+Q\left(X, Z_{j}\right)+e_{j}
$$

\footnotetext{
${ }^{3}$ See, for example, Lavy and Quigley (1993); Thomas, Lavy and Strauss (1992); World Bank (1990).

${ }^{4}$ The only other study of health demand from Africa that we are aware of that includes quality variables is by Mwabu, Ainsworth and Nyamete (1993) for Kenya.

${ }^{5}$ Dow $(1995,1999)$ gives a thorough review of this type of model.
} 
where $\left(y-p_{j}\right)$ is net income after paying for health care option $j ; X$ is a set of individual or household variables that do not vary with the discrete choice; and $Z_{j}$ is a set of choicespecific variables. The function $Q\left(X, Z_{j}\right)$ indicates the quality of option $j$, and is a function of that choice's own characteristics, as well as individual and household characteristics of the demander. Thus, we assume that utility depends on the quality of health care received, and on consumption of all other goods (net income).

In our model, the quality function $\mathrm{Q}\left(\mathrm{X}, \mathrm{Z}_{\mathrm{j}}\right)$ is linear in the $\mathrm{X}$ and $\mathrm{Z}$ variables. The $\mathrm{X}$ variables include age, education, marital status, duration of illness, and household demographics. In all cases, we allow these coefficients to vary across options.

The $\mathrm{Z}_{\mathrm{j}}$ variables are more problematic. These are option-specific variables, which in our case are variables measuring the quality of each service option. Unfortunately, the survey asks these questions only about the nearest public clinic. There are no data on the quality of the other options. Thus, we have a left-out variable problem, which may be particularly important for the estimate of the price parameter, since one would expect price and quality to be positively correlated. While we will discuss this problem further in the results section, we attempt to assess its magnitude by determining how much the price parameters differ with the exclusion of the public quality variables.

The functional form for prices and income is quadratic in the logs of net income:

$$
f\left(y-p_{j}\right)=\beta_{1} * \ln \left(y-p_{j}\right)+\beta_{2} *\left[\ln \left(y-p_{j}\right)\right]^{2}
$$

where we keep the $\beta$ 's equal across options. This constrains the marginal utility of income to be the same across options. While there is some debate about whether this is necessary to be consistent with utility maximization (McFadden, 1981; Dow, 1999), having radically different marginal utilities across options, which unconstrained estimates often produce, seems implausible.

As with all discrete choice models, the logit identifies only the difference in utilities, $\mathrm{V}_{\mathrm{j}}-\mathrm{V}_{0}$, where $\mathrm{V}_{0}$ is a reference or base utility, in our case, self-care. In particular, we normalize the quality of self-care to zero. In addition, the function $\mathrm{f}\left(\mathrm{y}-\mathrm{p}_{\mathrm{j}}\right)$ will be very similar across options as costs are small relative to income. Because this complicates the optimization, we approximate the function:

$$
\begin{aligned}
\mathrm{f}\left(\mathrm{y}-\mathrm{p}_{\mathrm{j}}\right) & =\beta_{1} * \ln \left(\mathrm{y}-\mathrm{p}_{\mathrm{j}}\right)+\beta_{2} *\left[\ln \left(\mathrm{y}-\mathrm{p}_{\mathrm{j}}\right)\right]^{2} \\
& =\beta_{1} *\left\{\ln (\mathrm{y})+\ln \left(1-\mathrm{p}_{\mathrm{j}} / \mathrm{y}\right)\right\}+\beta_{2} *\left\{\left[\ln (\mathrm{y})+\ln \left(1-\mathrm{p}_{\mathrm{j}} / \mathrm{y}\right)\right]^{2}\right\} \\
& =\beta_{1} *\left\{\ln (\mathrm{y})+\ln \left(1-\mathrm{p}_{\mathrm{j}} / \mathrm{y}\right)\right\}+\beta_{2} *\left\{\ln (\mathrm{y})^{2}+2 \ln (\mathrm{y}) \ln \left(1-\mathrm{p}_{\mathrm{j}} / \mathrm{y}\right)+\ln \left(1-\mathrm{p}_{\mathrm{j}} / \mathrm{y}\right)^{2}\right\} \\
& \approx \beta_{1} *\left\{\ln (\mathrm{y})-\mathrm{p}_{\mathrm{j}} / \mathrm{y}\right\}+\beta_{2} *\left\{\ln (\mathrm{y})^{2}-2 \ln (\mathrm{y})\left(\mathrm{p}_{\mathrm{j}} / \mathrm{y}\right)\right\}
\end{aligned}
$$

Both $\ln (\mathrm{y})$ and its square are constant across options, so that after taking the difference $\mathrm{V}_{\mathrm{j}}-\mathrm{V}_{0}$, only $\beta_{1}\left(-\mathrm{p}_{\mathrm{j}} / \mathrm{y}\right)-\beta_{2}\left\{2 \ln (\mathrm{y})\left(\mathrm{p}_{\mathrm{j}} / \mathrm{y}\right)\right\}$ remains. Note that this still identifies the two coefficients of interest. 
Nesting the logit choices allows us to estimate at least some of the covariances between the $e_{j}$ 's, which in turn allows cross-price elasticities to vary between options. Figure 1 presents the nesting that we estimate. The probability that a person chooses option $\mathrm{k}$ is given by

$$
\pi_{l}=\frac{\left[\exp \left(\frac{V_{l}}{\sigma_{j(l)}}\right)\right]\left[\sum_{i \in j(l)} \exp \left(\frac{V_{i}}{\sigma_{j(l)}}\right)\right]^{\left(\sigma_{j(l)} / \tau_{k(l)}-1\right)}\left[\sum_{j \in k(l)}\left[\sum_{i \in j(l)} \exp \left(\frac{V_{i}}{\sigma_{j}}\right)\right]^{\left.\left(\sigma_{j(l)} / \tau_{k(l)}\right)\right]^{\tau_{k(l)}}}\right.}{\sum_{k}\left(\sum_{j}\left[\sum_{i \in j} \exp \left(\frac{V_{i}}{\sigma_{j}}\right)\right]^{\sigma_{j} / \tau_{k}}\right)^{\tau_{k}}}
$$

where $\mathrm{i}$ indexes the individual options (private hospital, etc.); $\mathrm{j}$ indexes the lower level nests (hospital care, or non-hospital care); and $\mathrm{k}$ indexes the upper level nest (no care or care). $V_{i}$ is the indirect utility associated with option $i ; \sigma_{j}$ is the inclusive value coefficient for the lower level nests; $\tau_{\mathrm{k}}$ is the inclusive value coefficient for the upper level nests (the limbs); and $\mathrm{j}(\mathrm{l})$ and $\mathrm{k}(\mathrm{l})$ indicate the lower and upper level nests to which option 1 belongs. Note that if all $\tau_{\mathrm{k}}$ are constrained to one, this reduces the one-level nested logit probability, and if the $\sigma_{\mathrm{j}}$ are also one, to a multinomial logit.

McFadden (1978) shows that if the model estimates satisfy the usual axioms of utility maximization, substitution will be more likely between members of a group than across groups. For example, if the price of private clinic services increases, demand will shift more than proportionately to public clinics, which are in the same nest. Given that we are interested in five different health care options, using a two-level nest is important. It permits us to estimate cross-price elasticities that vary for all choices. Thus, we avoid the red bus/blue bus problem not only for the no care vs. some health care option, but also for hospital vs. clinic-based care.

\section{DATA}

In this study we use the Tanzania Human Resource Development Survey, conducted by the World Bank in collaboration with the University of Dar es Salaam and the Government of Tanzania's Planning Department. The survey took place between August 1993 and January 1994, and covered 5184 households. In our work, however, we only use the rural sample, comprising around 2200 households and slightly more than 14,000 individuals. Of those, around 15 percent report having been sick or injured in the past four weeks, and we limit our estimates to this sample. Thus, all results are conditional on having been sick or injured.

The HRD survey is similar to other multi-topic surveys recently conducted in Africa, following the broad outlines of the Living Standards Measurement Surveys 
(Grosh and Glewwe, 1995). In addition to health care, the survey collects information on household expenditures, education, and demographics. An important limitation of the survey is the lack of an accompanying community survey. ${ }^{6}$ As a result, the limited information that we have about the providers is derived from the household questionnaire. In particular, respondents evaluate the quality of the nearest public clinic in regard to the availability of drugs needed when seeking treatment; the availability of qualified doctors and nurses; and the quality of the facility's environment, in terms of having a toilet, water, and a covered waiting room. These responses are ordinal- very poor, poor, adequate, good, and very good - but there are few responses at the extremes, so we reduced the categories to three: poor, adequate, and good. Since a given household's responses to these questions may be correlated with the unobserved errors, $e_{j}$, of its utility for option $j$, we use cluster level variables that correspond to the share of households within a given cluster responding poor, adequate and good. In a few cases, there were less than four quality observations in a cluster, so we used district-level means.

In terms of the cost of each option, we ran into serious difficulties because the direct costs (user fees and charges for medicines and supplies) were missing in many cases, and in cases where they are recorded, they are so varied that it is impossible to derive a meaningful measure of average costs per visit at a sufficiently disaggregated level. Therefore, we exclude these data from our cost variable, including only the indirect or opportunity costs that result from lost work associated with travel to the health facility.

\section{RESULTS}

Table 1 presents three models for estimated health care demand functions. The first is a base model, with the quality variables, which are collected in reference to the public clinics and dispensaries, entered only in the public clinic and dispensary option. The second includes the doctor/nurse quality variable in all options, for reasons that we discuss below. The third includes no quality variables, allowing an assessment of the left-out variables bias.

Recall that the model first nests options by no care/care, then by hospital/nonhospital care, then by public/private facility. At each level, the inclusive value parameter on the base option, no care, is normalized to one. In all models, the values of the inclusive value parameters, $\sigma_{\mathrm{j}}$ and $\tau_{\mathrm{k}}$, are between zero and one, which indicates that the nested model is consistent with utility maximization. Lower values of these parameters (closer to zero) indicate a higher degree of correlation between the unobserved component of indirect utility for the options in the nest, which we interpret as a higher

\footnotetext{
${ }^{6}$ More detail is required to catalogue the set of health care options, the cost of accessing them, and the quality of services provided through interviews with both patients and community informants. This implies, in fact, that complementary to the collection of household data, further research would benefit from something like a health care services survey that has comprehensive coverage and detailed quality information and costs incorporated.
} 
degree of substitutability between these options relative to the others. For example, public and private non-hospital service show a very high degree of substitutablity.

We can use these price parameters to calculate the price responsiveness of individuals to their health care choices. Table 2 summarizes the price elasticities for each health care option with respect to each option's price, calculated for the entire sample on the basis of the second model reported in Table 1. (As we will discuss below, the price elasticities were nearly identical for all three models shown.) Perhaps the most important finding is that the own price elasticities (on the diagonal) are quite variable, being far greater than unity for private clinics, private hospitals, and public hospitals. While our estimates appear to be high for hospital visits, one has to keep in mind that our model has five options rather than the usual three or two. This by itself will lead to more elastic demand for a given option, even if the overall demand for health care is inelastic. In addition, we are not able to distinguish between inpatient and outpatient visits. For example, in Ghana, Lavy and Quigley (1993) find that the price elasticity for inpatient visits is -1.82 , while only -0.25 for outpatients.

We have also estimated cross price elasticities, evaluated at mean prices, which all have the expected positive signs (Table 2). The substitution effects are particularly high between public clinics and private clinics. Specifically, we find an uncompensated elasticity of demand for private services with respect to the price of public clinics and dispensaries to be a surprisingly high, 0.64. This indicates that as prices of public services rise, there will be a substantial substitution into private services. In the other direction, the price elasticity of public clinics with respect to the price of the private alternative is 0.58 , implying a high, albeit somewhat smaller, degree of price sensitivity. There are also relatively high cross price effects between public and private hospitals. In contrast, we find that the substitution between non-hospital and hospital care is far smaller. Specifically, the elasticity of demand for private and public hospital care with respect to the price of care in public clinics is 0.08 .

Even though the own-price elasticities are high in these estimates, the high crossprice parameters in many cases means that a price increase for any one service mostly causes substitution into other health care services rather than a lack of care. ${ }^{8}$ The total elasticity of demand for health care with respect to the price of a public hospital has the largest absolute value, but it is still only -0.053 . The total elasticity of demand for private non-hospitals is the lowest, -0.035 . Thus, as long as only one price increases, most of the substitution will be to other health care services rather than no care. Only if all prices rise simultaneously would the demand for health care fall measurably, albeit still in rather modest way, as represented by an elasticity of total demand with respect to the price of all services of -0.17 .

\footnotetext{
${ }^{7}$ The elasticities are calculated analytically, at the sample mean price for each type of service.

${ }^{8}$ This is in keeping with similar findings from Indonesia (Gertler and Molyneaux 1997), and Lesotho (Bennet 1989).
} 
Table 3 gives the observed probability of choosing each option, as well as the partial elasticities of demand that show the absolute level of change in the probability of choosing a specific health care option for a percent change in the price. These parameters are more easily interpreted than the elasticities presented above. For example, we find that a doubling of the price of public clinics or public hospitals will result in a decline in the probability of their use of 0.10 ; or that the decline in the probability of visiting a private care provider outside of a hospital is 0.19 when the price of that category of care doubles (despite that the own-price elasticity of demand is 1.69). In terms of cross price effects, while the elasticity of private clinics with respect to the price of public clinics is 0.63 , the change in probability in the use of private clinics with respect to a doubling of price of public clinics is only 0.07. But perhaps the most important finding that emerges from these cross-price effects is that most of the decline in use of public clinics, as a result of a price increase, is absorbed by private clinics, and there is a relatively small increase in the probability of choosing the no care option. A similar pattern holds for private clinics, where a doubling of price is accompanied by a large increase in the use of public clinics, and only a small increase in the probability of self-care. As a result, for example, doubling the price of public clinics will only result in a small decline in probability of receiving care of -0.021 . The comparable parameter for public hospital is around the same magnitude, -0.029 . It is also noteworthy that the overall change in probability of seeking out any care, as a result of a doubling of price of all care options, is only 0.093 .

Finally, we examine how the impact of price changes on care varies by income groups. Table 4 shows the own-price elasticities reported by expenditure quartile. In all cases, we find that the poor are far more responsive to prices than the non-poor. This finding, too, is consistent with the large variation in price elasticities across expenditure groups reported in other research. It also implies that policies such as user fees and subsidies will have a much greater impact on service utilization of lower income households. But again, the more interesting story emerges in Table 5, which reports the change in the probability of receiving any care as a result of a doubling of the price of the options, disaggregated by expenditure quartile. Even though people at the lower end of the income distribution are more price responsive, the actual changes in the probability of care are small for everyone, except for the case when all prices rise. For example, the effect of doubling the price of public clinics and dispensaries on the probability of use of any type of care is 0.040 for the poorest quartile and 0.001 for the highest. Even when all prices double, use of any care declines by .172 in the poorest quartile, while it remains less than 0.01 for the richest.

Turning our attention to the effect of quality on health care demand, in the first model, where we enter the quality variables only in the public clinic option to which they pertain, we find that there is greater demand for public clinics and dispensaries in those clusters with higher quality ratings for drug availability and the health clinic environment. In both those cases, the parameter estimate is greater for the high quality dummy than the average rating, indicating that the level of quality also matters. For the quality variable on doctor, however, we get the unexpected finding of a negative and significant parameter estimate on the high quality dummy variable. One possible 
explanation for this anomaly is that, while drugs and environment are specific to the public clinic, the doctor or nurse who works at the public clinic may well attend at the nearest hospital, and may moonlight at a private practice. Thus, the same clusters with high quality staff at the public clinic may have high quality staff at hospitals and private clinics as well.

To explore this possibility, the second column of Table 1 shows the results of a model that includes the doctor/nurse quality variables in the indirect utility function for each health care option. The doctor/nurse quality variables now have positive coefficients in the public clinic option, although they are only significant in the case of high quality, and only with a relatively small parameter estimate. In the case of the other options, particularly private clinics, we get larger positive and highly significant parameter estimates for both the adequate and good quality dummies, with the latter being three times the magnitude of the former. One interpretation of this is that higher quality medical staff in a community increases the demand for care, but mostly in hospitals and private clinics, where they see most of their patients and are most accessible. ${ }^{9}$

The demand estimates permit us to calculate the change in probability of utilization of health care options for discrete changes in the quality of public clinics and dispensaries. The results in Table 6 indicate that raising the quality of doctor care from low to high, for example, reduces the no care option by 0.2541 for the entire sample. The large increase in demand as a result of this policy change is mostly found in private clinics. Improving the quality of drugs availability at public clinics, from low to high, increases the probability of choosing care at a public clinic by .110 , mostly as a result of a decline in demand in private clinics. Overall, the increase in the probability of demanding any health care is only 0.02. We get a similar story when it comes to improvements in the quality of the health environment. Most of the large, quality induced, increase in probability of demand for public clinics $(0.27)$, comes at the expense of a decline in the demand for private clinics. Overall, there is only a 0.073 increase in the probability of seeking treatment as a result of the increase in the quality of the environment from low to high. We should also note that unlike the responsiveness to prices, that quality improvements have the same order of change in demand across expenditure quartiles.

The weak link in this analysis is that we do not have any objective measure of what the population views as "poor," "adequate," or "good" quality. While the findings on quality are of interest, their value in terms of providing policy guidance is limited since we cannot determine the costs of quality improvements that are required to induce the increase in treatment received. The other parameters in the model generally conform to our expectations. The education dummy variables, which are indexed on choice of provider, generally show the same pattern of increasing demand as education

\footnotetext{
${ }^{9}$ It is also possible that there is a correlation of quality across providers, e.g., a less remote area will have better quality for all provider types, so public clinic characteristics proxy those in other facilities. This would be the case if, for example, the existence of high quality services at the public clinic forced private clinics to provide even higher quality services in order to attract patients.
} 
increases across all options. Interestingly, the rate of increase in demand with more education is greatest for public hospitals, and next for private hospitals, while the rate of increase in demand as education rises is lowest in the case of public non-hospital services. For the dummy variables that show how age affects the probability of seeking treatment, we find that relative to the left out category of children under the age of 5, all age groups are less likely to seek care from all types of providers. Adults are more likely to seek care at both public and private hospitals than children under 5, while just the opposite is the case for children 5 to 14 and young adults 15 to 21 . The age group least likely to seek care across all treatment categories is 15 to 21 year olds.

The negative sign on the gender dummy variables indicates that for all treatment options, men are less likely to seek out available treatments. This tendency seems somewhat more pronounced for public clinics and dispensaries. ${ }^{10}$ While we would have expected persons from larger households to be less likely to seek care, because of competition for resources in the household, this finding is limited to non-hospital care. And finally, we note that the longer the duration of reported illness, the greater the probability of demanding all treatment options except public clinics and dispensaries. This may reflect that treatment from public clinics is sought for relatively minor cases of illness, or in the earlier stages of disease.

Finally, we present one more set of models in column three that excludes the quality variables. Our interest is to determine to what extent the exclusion of quality factors might bias the price parameters. We find that there is hardly any change in the price coefficient, or other parameters, with the inclusion of the quality variables. This finding suggests that the potential bias from lack of information on the quality of other health care options may not be important for our estimates. ${ }^{11}$

\section{SUMMARY AND CONCLUSIONS}

Our research has estimated a nested multinomial logit model of health care demand for Tanzania, adding to the limited number of research papers in this area by, in combination, employing a two tier nesting scheme, modeling a greater number of health options that is usually the case - public clinics, public hospital private clinics and private hospitals - as well as by including quality variables in the models.

Two important policy conclusions emerge from this exercise. First, we have shown that quality is an important determinant of health demand. This applies to the quality and availability of doctors/nurses, drugs, and the clinic environment. The demand for health care will increase if people have the option to see a better doctor/nurse, get

\footnotetext{
${ }^{10}$ This finding has nothing to do with normal pregnancy related visits, which the illness and consultation data exclude.

${ }^{11}$ Since our price variable is based on opportunity cost of time in seeking care, it is possible that the if direct costs, in the form of fees, were included, the absence of quality effects would have a larger impact on the price parameters. This is because the expected connection is that facilities that offer better services will charge higher fees.
} 
access to pharmaceuticals, and attend a health center, clinic and dispensary that is cleaner, has a toilet and water, and a roof. However, in the case of improvements in the quality of doctors/nurses in public clinics and dispensaries, it appears that the increase in treatment will be primarily in private clinics, even though the variable we include in the models is the quality of public clinic doctors/nurses. We can offer a reasonable explanation for this finding that is consistent with anecdotal evidence: doctors and nurses working in public clinics often have private practices. Unfortunately, we do not have any information that would help us understand the process by which patients and staff time are allocated between public and private services.

The main weakness of our quality data is that the variables are subjective and qualitative. Simply asking households to provide an ordinal assessment the quality of health care services along various general dimensions, as is done in HRDS, prevents us from estimating the costs of providing better quality. Thus, we know that people value adequate doctors better than poor ones, and good doctors better than adequate, and we could estimate the willingness to pay for these changes, but the survey data do not allow us to estimate the corresponding cost of the providing changes. Thus, we are unable to make calculations similar to those in Litvack and Bodart (1993) or Gertler and van der Gaag (1990) with these data. It would be far more useful to collect data on specific, costable, attributes of health delivery options

The second important message from this paper is that consumers in Tanzania are highly responsive to the price of health care, and that this responsiveness is greater for individuals at the lower end of the income distribution. Own price elasticities are high, although, less so for public clinics and dispensaries than other options. When prices of services are increased, there will be a precipitous decline in use of those services. This comes as no surprise, both in light of previous research on health demand, and the evidence from countries, such as Ghana (Waddington and Enyimayew, 1990), Kenya (Mwabu, 1989), Swaziland (Yoder, 1989) and Zambia (Kahenya and Lake, 1994), which have reported declines in the use of public clinics subsequent to the imposition of user fees. However, where our research sheds new light is on the high degree of substitution between public and private care. Consequently, price increases or user fees will result in a small percentage of people opting for self-treatment. This is true even if the private sector responds to the shift in demand by raising its own prices. Likewise, there is evidence that government should have as its major goal improving the quality of care, regardless of whether it is in the private or public sector. The fact that private and public health care are close substitutes directs our attention away from the public provision of services per se, toward the more general goal of expanding the size and improving the quality of the health care system in its entirety. 


\section{REFERENCES}

Bennet, S. (1989). 'The Impact of the Increase in User Fees', Lesotho Epidemiological Bulletin, Vol. 4.

Dor, A., Gertler, P. and van der Gaag, J. (1987). 'Non-Price Rationing and the Choice of Medical Care Providers in Rural Côte d'Ivoire', Journal of Health Economics, Vol. 6, 291-304.

Dow, W. (1999). 'Flexible Discrete Choice Demand Models Consistent with Utility Maximization: An Application to Health Care Demand', American Journal of Agricultural Economics, Vol. 81, 680-85.

Dow, W. (1995). 'Unconditional Demand for Curative Health Inputs: Does Selection on Health Status Matter in the Long Run?' Labor and Population Program Working Paper Series, 95-22, RAND (DRU-1234-RC).

Gertler, P. and Molyneaux, J. (1997). 'Experimental Evidence on the Effect of Raising User Fees for Publicly Delivered Health Care Services: Utilization, Health Outcomes, and Private Provider Response', RAND, Santa Monica, CA.

Gertler, P. and van der Gaag, J. (1990). The Willingness to Pay for Medical Care: Evidence from Two Developing Countries. Johns Hopkins University Press, Baltimore, MD.

Gertler, P., Locay, L. and Sanderson, W. (1987). 'Are User Fees Regressive? The Welfare Implications of Health Care Financing Proposals in Peru', Journal of Econometrics, Vol. 36 (supplement), 67-88.

Grosh, M. E. and Glewwe, P. (1995). 'A Guide to Living Standards Measurement Study Surveys', Living Standards Measurement Study Working Paper \#120, World Bank, Washington, DC.

Glick, P., Razafindravonona, J. and Randretsa, I. (2000). 'Education and Health Services in Madagascar: Utilization Patterns and Demand Determinants', Cornell Food and Nutrition Policy Program Working Paper No. 107, Cornell University, Ithaca, NY.

Kahenya, G. and Lake, S. (1994). User Fees and their Impact on Utilization of Key Health Services, UNICEF, Lasaka.

Lavy, V. and Quigley, J. M. (1993). 'Willingness to Pay for the Quality and Intensity of Medical Care: Low-Income Households in Ghana,' World Bank Living Standards Measurement Study Working Paper No. 94, World Bank, Washington, DC. 
Litvack, J. and Bodart, C. (1993). 'User Fees Plus Quality Equals Improve Access to Health Care: Results of a Field Experiment in Cameroon', Social Science and Medicine, Vol. 37, 369-83.

McFadden, D. (1981). 'Econometric Models of Probabilistic Choice', in Manski, C. and McFadden, D. (eds), Structural Analysis of Discrete Data: With Econometric Applications, MIT Press, Cambridge, MA.

McFadden, D. (1978). 'Modelling the Choice of Residential Location', in Karquist, A. et. al. (eds), Spatial Interaction Theory and Residential North Holland, Amsterdam.

Mwabu, G., Ainsworth, M. and Nyamete, A. (1993). 'Quality of Medical Care and Choice of Medical Treatment in Kenya: An Empirical Analysis', Journal of Human Resources, Vol. 28, 838-62.

Mwabu, G., Mwanzia, J. and Laimbila, W. (1995). 'User Charges in Government Health Facilities in Kenya', Health Policy and Planning, Vol. 10, 164-70.

Thomas, D., Lavy, V. and Strauss, J. (1992). 'Public Policy and Anthropometric Outcomes in Côte d'Ivoire.' Living Standards Measurement Study 89, World Bank, Washington, DC.

Waddington, C. J. and Enyimayew, K.A. (1990). 'A Price to Pay: The Impact of User Charges in the Volta Region of Ghana', International Journal of Health Planning and Management, Vol. 5, 287-312.

World Bank (1990). Kenya: Human Resources_Improving Quality and Access. World Bank, Washington, DC.

Yoder, R. (1989). 'Are People Willing and Able to Pay for Health Services?' Social Science and Medicine, Vol. 29, 35-42.

Younger, S. (1999). 'The Relative Progressivity of Social Services in Ecuador', Public Finance Review, Vol. 27, 310-52. 
TABLE 1

Health Care Demand Models

\begin{tabular}{|c|c|c|c|c|c|c|}
\hline \multirow[b]{2}{*}{ Variable/Category } & \multicolumn{2}{|c|}{$A$} & \multicolumn{2}{|l|}{$B$} & \multicolumn{2}{|c|}{$C$} \\
\hline & Coefficient & T-Value & Coefficient & T-Value & Coefficient & T-Value \\
\hline \multicolumn{7}{|l|}{ PUBLIC HOSPITAL } \\
\hline Constant & -1.6761 & -1.8020 & -2.4056 & -2.2235 & -1.6250 & -1.9130 \\
\hline \multicolumn{7}{|l|}{ Age of ill/injured person } \\
\hline Age 5-14 & -0.7291 & -2.8123 & -0.7729 & -2.8453 & -0.7371 & -3.7746 \\
\hline Age 15-21 & -0.5555 & -1.4670 & -0.6681 & -1.6363 & -0.5626 & -1.6775 \\
\hline Age $22-49$ & 0.1570 & 0.3317 & -0.0146 & -0.0306 & 0.1316 & 0.3094 \\
\hline Age $>50$ & 0.4203 & 0.8014 & 0.1671 & 0.3258 & 0.3914 & 0.7845 \\
\hline \multicolumn{7}{|l|}{ Ed ill/injured person or mother } \\
\hline Primary Education & 0.5342 & 2.2086 & 0.5205 & 2.2226 & 0.5322 & 3.0409 \\
\hline Secondary Education & 0.8924 & 3.5830 & 0.8742 & 3.3053 & 0.8857 & 3.9042 \\
\hline Post-Secondary Education & 2.5338 & 5.1776 & 2.2912 & 4.5378 & 2.5098 & 5.1959 \\
\hline Household Size & 0.2028 & 0.9112 & 0.1411 & 0.6520 & 0.1951 & 1.1305 \\
\hline Married & -0.2911 & -1.0996 & -0.2552 & -0.9698 & -0.2807 & -1.2352 \\
\hline Length of Illness & 0.0008 & 3.0143 & 0.0008 & 3.0832 & 0.0008 & 2.9947 \\
\hline Gender & -0.2493 & -1.6125 & -0.2410 & -1.4279 & -0.2450 & -2.2675 \\
\hline Ln consumption & 69.20 & 3.45 & 59.91 & 2.92 & 67.95 & 3.07 \\
\hline Ln consumption sq & -17.0505 & -3.4201 & -14.8021 & -2.8939 & -16.6892 & -3.0674 \\
\hline Adequate Doctor Quality & & & 1.5194 & 2.2336 & & \\
\hline Good Doctor Quality & & & 1.7860 & 2.8489 & & \\
\hline Sigma & 0.6790 & $0.2262^{*}$ & 0.5767 & $.2325^{\star}$ & 0.6700 & $.2178^{*}$ \\
\hline Tau & 0.9573 & $.3215^{\star}$ & 0.7821 & $0.2903^{*}$ & 0.9378 & $.2982^{*}$ \\
\hline \multicolumn{7}{|l|}{ PRIVATE HOSPITAL } \\
\hline Constant & -1.4360 & -1.6928 & -1.4485 & -1.7768 & -1.3883 & -1.8077 \\
\hline \multicolumn{7}{|l|}{ Age of ill/injured person } \\
\hline Age 5-14 & -0.7505 & -2.9719 & -0.8075 & -3.3930 & -0.7563 & -3.8648 \\
\hline Age 15-21 & -0.9117 & -2.4995 & -0.9831 & -2.8042 & -0.9158 & -3.3176 \\
\hline Age 22-49 & 0.1899 & 0.4022 & -0.0001 & -0.0003 & 0.1676 & 0.4046 \\
\hline Age $>50$ & 0.3838 & 0.7427 & 0.1422 & 0.2862 & 0.3604 & 0.7849 \\
\hline \multicolumn{7}{|c|}{ Ed ill/injured person or mother } \\
\hline Primary Education & 0.3275 & 1.2205 & 0.3294 & 1.4018 & 0.3258 & 1.9752 \\
\hline Secondary Education & 1.1861 & 4.0600 & 1.0991 & 4.0450 & 1.1784 & 4.2705 \\
\hline Post-Secondary Education & 1.7476 & 3.4996 & 1.6610 & 3.3322 & 1.7402 & 4.5987 \\
\hline Household Size & 0.0439 & 0.2305 & 0.0219 & 0.1052 & 0.0382 & 0.2474 \\
\hline Married & -0.7638 & -2.2634 & -0.6388 & -2.0188 & -0.7503 & -2.5913 \\
\hline Length of Illness & 0.0007 & 2.4388 & 0.0006 & 2.5130 & 0.0007 & 2.5699 \\
\hline Gender & -0.3284 & -2.0701 & -0.3046 & -1.7320 & -0.3233 & -2.7552 \\
\hline Ln consumption & -69.2013 & -3.4537 & -59.9060 & -2.9161 & -67.9505 & -3.0709 \\
\hline Ln consumption sq & -17.0505 & -3.4201 & -14.8021 & -2.8939 & -16.6892 & -3.0674 \\
\hline Adequate Doctor Quality & & & 0.7035 & 1.1302 & & \\
\hline Good Doctor Quality & & & 0.5241 & 0.7217 & & \\
\hline
\end{tabular}


TABLE 1 continued

Health Care Demand Models

\begin{tabular}{|c|c|c|c|c|c|c|}
\hline \multirow[b]{2}{*}{ Variable/Category } & \multicolumn{2}{|c|}{$A$} & \multicolumn{2}{|l|}{$B$} & \multicolumn{2}{|c|}{$C$} \\
\hline & Coefficient & T-Value & Coefficient & T-Value & Coefficient & T-Value \\
\hline \multicolumn{7}{|c|}{ PRIVATE HOSPITAL continued } \\
\hline Sigma & 0.6790 & $0.2262^{*}$ & 0.5767 & $.2325^{\star}$ & 0.6700 & $.2178^{*}$ \\
\hline Tau & 0.9573 & $.3215^{\star}$ & 0.7821 & $0.2903^{*}$ & 0.9378 & $.2982^{*}$ \\
\hline \multicolumn{7}{|l|}{ PUBLIC NON-HOSPITAL } \\
\hline Constant & 0.8836 & 5.3279 & 0.3070 & 1.2050 & 1.0009 & 7.2905 \\
\hline \multicolumn{7}{|l|}{ Age of ill/injured person } \\
\hline Age 5-14 & -1.0779 & -7.7038 & -1.0673 & -7.3781 & -1.0702 & -7.2284 \\
\hline Age $15-21$ & -1.4312 & -6.6345 & -1.4096 & -6.7157 & -1.4210 & -6.7302 \\
\hline Age $22-49$ & -1.0686 & -5.1645 & -1.0400 & -5.8778 & -1.0691 & -5.1113 \\
\hline Age $>50$ & -1.1341 & -5.6789 & -1.1133 & -6.2751 & -1.1384 & -5.4235 \\
\hline \multicolumn{7}{|c|}{ Ed ill/injured person or mother } \\
\hline Primary Education & 0.3390 & 2.5134 & 0.3399 & 2.5251 & 0.3379 & 2.4967 \\
\hline Secondary Education & 0.5040 & 3.5415 & 0.5297 & 3.5175 & 0.4848 & 3.1136 \\
\hline Post-Secondary Education & 1.1109 & 3.3911 & 1.1038 & 4.0894 & 1.1064 & 3.4748 \\
\hline Household Size & -0.2470 & -2.0264 & -0.2221 & -1.7052 & -0.2568 & -1.9723 \\
\hline Married & 0.1239 & 0.7719 & 0.0932 & 0.6982 & 0.1327 & 0.8084 \\
\hline Length of IIIness & 0.0001 & 0.5550 & 0.0002 & 0.7819 & 0.0002 & 0.6178 \\
\hline Gender & -0.2348 & -2.4801 & -0.2314 & -2.3767 & -0.2334 & -2.5087 \\
\hline Ln consumption & 69.20 & 3.45 & 59.91 & 2.92 & 67.95 & 3.07 \\
\hline Ln consumption sq & -17.0505 & -3.4201 & -14.8021 & -2.8939 & -16.6892 & -3.0674 \\
\hline Adequate Doctor Quality & -0.0016 & -0.0135 & 0.3595 & 0.9923 & & \\
\hline Good Doctor Quality & -0.4428 & -2.5886 & 0.9454 & 2.3921 & & \\
\hline Adequate Drug Quality & 0.3414 & 2.2092 & 0.2944 & 1.9147 & & \\
\hline Good Drug Quality & 0.1927 & 1.1380 & 0.1650 & 0.9482 & & \\
\hline Adequate Environ. Quality & -0.0042 & -0.0423 & -0.0043 & -0.0416 & & \\
\hline Good Environ. Quality & 0.5477 & 2.6049 & 0.4786 & 2.3790 & & \\
\hline Sigma & 0.1854 & $0.0603^{*}$ & 0.1608 & $.0589^{\star}$ & 0.1662 & $0.059^{*}$ \\
\hline Tau & 0.9573 & $.3215^{\star}$ & 0.7821 & $0.2903^{*}$ & 0.9378 & $.2982^{*}$ \\
\hline \multicolumn{7}{|l|}{ PRIVATE NON-HOSPITAL } \\
\hline Constant & 0.7904 & 4.9107 & 0.2007 & 0.7825 & 0.8350 & 5.5458 \\
\hline \multicolumn{7}{|l|}{ Age of ill/injured person } \\
\hline Age 5-14 & -1.0663 & -7.4755 & -1.0571 & -7.2020 & -1.0656 & -7.1768 \\
\hline Age $15-21$ & -1.4399 & -6.5719 & -1.4170 & -6.6509 & -1.4237 & -6.7250 \\
\hline Age 22-49 & -1.0810 & -5.1354 & -1.0506 & -5.8189 & -1.0686 & -5.0989 \\
\hline Age $>50$ & -1.2513 & -5.8661 & -1.2154 & -6.3043 & -1.2324 & -5.5860 \\
\hline \multicolumn{7}{|c|}{ Ed of injured/ill person or mother } \\
\hline Primary Education & 0.3658 & 2.6407 & 0.3646 & 2.6335 & 0.3582 & 2.6243 \\
\hline Secondary Education & 0.5629 & 3.9273 & 0.5810 & 3.8037 & 0.5547 & 3.5782 \\
\hline Post-Secondary Education & 1.2519 & 3.9002 & 1.2209 & 4.5870 & 1.2430 & 3.9230 \\
\hline
\end{tabular}


TABLE 1 continued

Health Care Demand Models

\begin{tabular}{|c|c|c|c|c|c|c|}
\hline \multirow[b]{2}{*}{ Variable/Category } & \multicolumn{2}{|l|}{$A$} & \multicolumn{2}{|l|}{$B$} & \multicolumn{2}{|c|}{$C$} \\
\hline & Coefficient & $T$-Value & Coefficient & T-Value & Coefficient & $T$-Value \\
\hline \multicolumn{7}{|c|}{ PRIVATE NON-HOSPITAL continued } \\
\hline Household Size & -0.2242 & -1.8414 & -0.2038 & -1.5645 & -0.2244 & -1.7539 \\
\hline Married & 0.2417 & 1.4093 & 0.1951 & 1.3213 & 0.2227 & 1.2719 \\
\hline Length of IIIness & 0.0002 & 0.9661 & 0.0003 & 1.1889 & 0.0002 & 0.9268 \\
\hline Gender & -0.2505 & -2.5811 & -0.2462 & -2.4530 & -0.2435 & -2.5646 \\
\hline Ln consumption & 69.20 & 3.45 & 59.91 & 2.92 & 67.95 & 3.07 \\
\hline Ln consumption sq & -17.0505 & -3.4201 & -14.8021 & -2.8939 & -16.6892 & -3.0674 \\
\hline Adequate Doctor Quality & & & 0.3631 & 1.0040 & & \\
\hline Good Doctor Quality & & & 1.3999 & 3.9431 & & \\
\hline Sigma & 0.1854 & $0.0603^{*}$ & 0.1608 & $.0589^{*}$ & 0.1662 & $0.059^{*}$ \\
\hline Tau & 0.9573 & $.3215^{\star}$ & 0.7821 & $0.2903^{*}$ & 0.9378 & $.2982^{*}$ \\
\hline \multirow{2}{*}{$\begin{array}{r}\text { Log Likelihood } \\
\text { Observations }\end{array}$} & \multicolumn{2}{|c|}{-2337} & \multicolumn{2}{|c|}{2327} & \multicolumn{2}{|c|}{-2364} \\
\hline & \multicolumn{2}{|c|}{1913} & \multicolumn{2}{|c|}{1913} & \multicolumn{2}{|c|}{1913} \\
\hline
\end{tabular}

*We report standard errors rather than t-statistics for the inclusive value coefficients 
TABLE 2

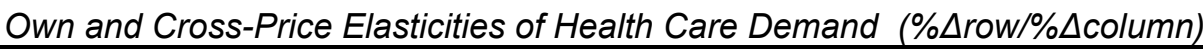

\begin{tabular}{lrcccc}
\hline & $\begin{array}{c}\text { Probability } \\
\text { of Choice }\end{array}$ & $\begin{array}{c}\text { Public } \\
\text { Hospital }\end{array}$ & $\begin{array}{c}\text { Private } \\
\text { Hospital }\end{array}$ & $\begin{array}{c}\text { Public } \\
\text { Clinic }\end{array}$ & $\begin{array}{c}\text { Private } \\
\text { Clinic }\end{array}$ \\
\hline No Care & 0.418 & 0.0757 & 0.0563 & 0.0536 & 0.0481 \\
Public Hospital & 0.057 & -1.8590 & 0.3345 & 0.0795 & 0.0713 \\
Private Hospital & 0.05 & 0.4205 & -1.6390 & 0.0795 & 0.0713 \\
Public Clinic & 0.333 & 0.1116 & 0.0837 & -0.3429 & 0.5826 \\
Private Clinic & 0.142 & 0.1116 & 0.0837 & 0.6388 & -1.6944 \\
ALL & 1 & -0.053 & -0.042 & -0.039 & -0.035
\end{tabular}




\section{TABLE 3}

Change in Probability of a Choice with Respect to a Percent Change in Price

\begin{tabular}{lcccc}
\hline & $\begin{array}{c}\text { Public } \\
\text { Hospital }\end{array}$ & $\begin{array}{c}\text { Private } \\
\text { Hospital }\end{array}$ & $\begin{array}{c}\text { Public } \\
\text { Clinic }\end{array}$ & $\begin{array}{c}\text { Private } \\
\text { Clinic }\end{array}$ \\
\hline No Care & 0.0292 & 0.0228 & 0.0215 & 0.0194 \\
Public Hospital & -0.0966 & 0.0176 & 0.0041 & 0.0037 \\
Private Hospital & 0.0203 & -0.0775 & 0.0036 & 0.0036 \\
Public Clinic & 0.0339 & 0.0260 & -0.1014 & 0.1675 \\
Private Clinic & 0.0133 & 0.0110 & 0.0722 & 0.1941 \\
ALL & -0.029 & -0.023 & -0.021 & -0.019
\end{tabular}


TABLE 4

Mean Own-Price Elasticities by Quartile

\begin{tabular}{lcccc}
\hline & $\begin{array}{c}\text { Public } \\
\text { Hospital }\end{array}$ & $\begin{array}{c}\text { Private } \\
\text { Hospital }\end{array}$ & $\begin{array}{c}\text { Public } \\
\text { Clinic }\end{array}$ & $\begin{array}{c}\text { Private } \\
\text { Clinic }\end{array}$ \\
\hline & 1 & 2 & 3 & 4 \\
Public Hospital & -3.4576 & -1.2552 & -0.5320 & -0.1344 \\
Private Hospital & -3.0454 & -1.1060 & -0.4745 & -0.1205 \\
Public Clinic & -0.6186 & -0.2445 & -0.1114 & -0.0310 \\
Private Clinic & -3.1610 & -1.1412 & -0.4740 & -0.1165
\end{tabular}




\section{TABLE 5}

Mean Change in Probability of Use of Any Health Care with Respect to Percent Change in Price of Each Option by Quartile

\begin{tabular}{lcccc}
\hline & $\begin{array}{c}\text { Public } \\
\text { Hospital }\end{array}$ & $\begin{array}{c}\text { Private } \\
\text { Hospital }\end{array}$ & $\begin{array}{c}\text { Public } \\
\text { Clinic }\end{array}$ & $\begin{array}{c}\text { Private } \\
\text { Clinic }\end{array}$ \\
\hline & 1 & 2 & 3 & 4 \\
Public Hospital & -0.0551 & -0.0187 & -0.0081 & -0.0024 \\
Private Hospital & -0.0427 & -0.0153 & -0.0062 & -0.0019 \\
Public Clinic & -0.0400 & -0.0145 & -0.0060 & -0.0014 \\
Private Clinic & -0.0346 & -0.0140 & -0.0065 & -0.0017 \\
ALL & -0.1724 & -0.0626 & -0.0268 & -0.0074
\end{tabular}




\section{TABLE 6}

Mean Change in Probability of Use for Raising Quality of Doctors/Nurses, Drugs and Environment from Low to High

\begin{tabular}{lllc} 
& Doctor & Drugs & Environment \\
\hline No Care & -0.2541 & -0.0213 & -0.0727 \\
Public Hospital & 0.0581 & -0.0041 & -0.0137 \\
Private Hospital & 0.0212 & -0.0037 & -0.0121 \\
Public Clinic & 0.1222 & 0.1102 & 0.2730 \\
Private Clinic & 0.3394 & -0.0811 & -0.1745
\end{tabular}


Figure 1 - Estimated nesting structure

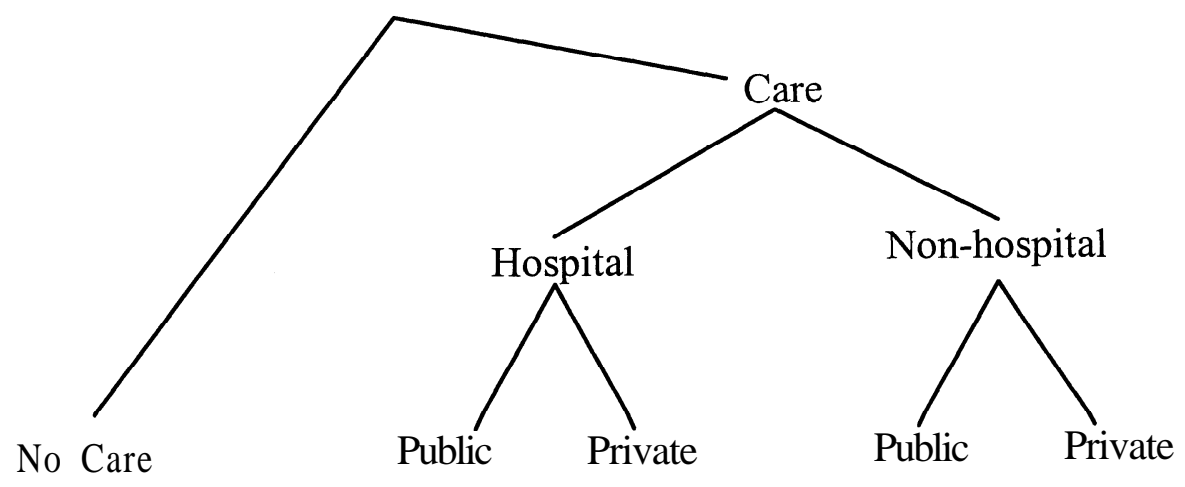

